\title{
Chronic Hepatitis (Chc), Viral Polymerase Nucleotide Inhibitor \& Process Patents Review and Evaluation, Preparation of Sofosbuvir
}

\author{
Krishna Sarma Pathy* \\ Head R\&D-QC/QA: IPL Research Centre, India \\ *Corresponding author: Krishna Sarma Pathy, Head R\&D-QC/QA: IPL Research Centre, India
}

\section{ARTICLE INFO}

Received: 㗀 September 27, 2019

Published: 幽 October 10, 2019

Citation: Krishna Sarma Pathy. Chronic Hepatitis (Chc), Viral Polymerase Nucleotide Inhibitor \& Process Patents Review and Evaluation, Preparation of Sofosbuvir. Biomed J Sci \& Tech Res 21(5)2019. BJSTR. MS.ID.003667.

Keywords: Chronic Hepatitis (Chc), Viral Polymerase Nucleotide Inhibitor \& Process Patents Review and Evaluation, Preparation of Sofosbuvir

\section{ABSTRACT}

Sofosbuvir is a viral polymerase nucleotide inhibitor that was approved in December 2013 by the United States Food and Drug Administration (FDA), and in January 2014 by the European Medicines Agency for the treatment of HCV infection [1]. The WHO Guidelines for the screening, care and treatment of persons with hepatitis $\mathrm{C}$ infection recommend sofosbuvir in combination with ribavirin in genotypes 1, 2, 3 and 4 HCV infection, either with or without pegylated interferon (depending on the HCV genotype) [2]. Sofosbuvir in combination with ribavirin is the first interferon-free HCV treatment. The fact that sofosbuvir is all oral simplifies the treatment and will allow expansion in low resource settings with poor health infrastructure.

a. The objective of this paper identify the most relevant process patents with respect to the medicines.

b. Identify in which countries these patents have been filed and granted.

This Article study mainly find numerous patents relating to preparation of Sofosbuvir. These patents will cover different aspects and innovations around the same product. Not all however are equally relevant, as many will cover variations or production processes but would not prevent somebody else to produce the medicine, e.g. by using a different process.

\section{Introduction}

Chronic Hepatitis C (Chc), Viral Polymerase Nucleotide Inhibitor

The World Health Organization's (WHO) 2014 Guidelines for the screening, care and treatment of persons with hepatitis C infection state that worldwide more than 185 million people are infected with the hepatitis C virus (HCV) [3]. Of these people, 350000 to 500000 die each year. An estimated one third of those who become chronically infected develop liver cirrhosis or hepatocellular carcinoma. HCV infection can be cured, but most people infected with the virus are unaware of their infection and so do not seek timely treatment. Furthermore, treatment remains unavailable for many who have been diagnosed. Several medicines are available to treat $\mathrm{HCV}$, including pegylated interferon and ribavirin but treatment duration is long, involves weekly injections, and side effects are considerable. With the development of new direct-acting antivirals, the treatment landscape is rapidly changing [4]. These new antivirals are expected to reach cure rates of more than $90 \%$ in persons with HCV infection across different genotypes, with fewer side effects and a shorter duration of treatment. Two new compounds, simeprevir and sofosbuvir, have recently been approved in the United States and Europe and are recommended by the new WHO treatment guidelines.

Many others are in various stages of development. Sofosbuvir is marketed by Gilead Sciences, Inc. under the brand names Sovaldi and Virunon. In 2011, Gilead Sciences acquired Pharmasset Ltd., the company that developed the drug and filed the first patent in 2003. Sofosbuvir is a prodrug that is metabolized in the body to the active antiviral agent 2 '-deoxy- 2 '- $\alpha$-fluoro- $\beta$-C-methyluridine- 
5'-monophosphate, a nucleotide analogue inhibitor of the HCV polymerase, which is critical for viral RNA replication. Sofosbuvir was invented by Pharmasset Ltd and developed by Gilead Sciences [5] (hereby referred to as the 'Sponsor').

\section{Discussion}

Resolution WHA67.6 adopted by the Sixty-Seventh World Health Assembly, requested the Director-General "to work with national authorities, upon their request, to promote comprehensive, equitable access to prevention, diagnosis and treatment for viral hepatitis" and "to assist Member States to ensure equitable access to quality, effective, affordable and safe hepatitis B and HCV treatments and diagnostics, in particular in developing countries". Ensuring access to new treatments is a challenging task. In order for countries to identify ways of increasing access and affordability of new HCV medicines, they need clarity about patent status [6]. To assess whether a medicine is patent protected in a certain country requires expert knowledge and access to specialized databases that are not easily available [7]. The WHO Global strategy and plan of action on public health, innovation and intellectual property provides WHO with a mandate to support efforts to determine the patent status of health products (element 5.1c). Despite the possibility of filing patents under the World Intellectual Property Organization (WIPO) Patent Cooperation Treaty (PCT) in 148 jurisdictions, there is no such thing as a worldwide patent. Patents are granted individually under each jurisdiction, depending on the national patent law and the outcome of the examination process. National patents that relate to the same basic patent (i.e. the same invention) are called family members and together build a patent family.

\section{Chemical Name}

Systematic (IUPAC) name: Isopropyl (2S)-2-[[[(2R,3R,4R,5R)5-(2,4-dioxopyrimidin-1-yl)-4-fluoro-3-hydroxy-4-methyltetrahydrofuran-2-yl]methoxy-phenoxy-phosphoryl]amino] propanoate. Sofosbuvir is a hepatitis $\mathrm{C}$ virus (HCV) nucleotide analog NS5B polymerase inhibitor indicated for the treatment of chronic hepatitis $\mathrm{C}$ (CHC) infection as a component of a combination antiviral treatment regimen. Sofosbuvir was approved by USFDA in 2013 and is marketed under the brand name Sovaldi®. It is indicated for the treatment for the treatment of chronic hepatitis C (CHC) infection as a component of a combination antiviral treatment regimen. Sovaldi ${ }^{\circledR}$, efficacy has been established in subjects with HCV [8] genotype 1, 2, 3 or 4 infection, [3] including those with hepatocellular carcinoma meeting Milan criteria (awaiting liver transplantation) and those with HCV/HIV-1 coinfection. Sofosbuvir is marketed in a crystalline free base form. It is a white to off-white crystalline solid with the empirical formula $\mathrm{C}_{22} \mathrm{H}_{29} \mathrm{FN}_{3} 0_{9} \mathrm{P}$ and a molecular weight of 529.45 Daltons. It is highly soluble compound and possessing solubility of $>2 \mathrm{mg} / \mathrm{mL}$ across the $\mathrm{pH}$ range of $2-7.7$ at $37^{\circ} \mathrm{C}$.

\section{Patent Evaluation}

As per the EMEA scientific discussion "Sofosbuvir is chiral molecule and possesses 6 stereogenic centers which are well controlled by the synthetic process and the specifications of raw materials. The absolute and relative configuration of these chiral centers was established by single crystal X-ray crystallography. Eight polymorphic forms of Sofosbuvir have been observed and the manufacturing process consistently produces Sofosbuvir as the most thermodynamically stable polymorphic form, containing a small amount of a metastable [5] form which were determined to be pharmaceutically equivalent as per ICH Q6A (decision tree \#4). Other polymorphic forms are excluded by the manufacturing process and their absence is confirmed by DSC "Sofosbuviris specifically disclosed in US 7,964,580 [9] (Figure 1). This patent discloses a process for the preparation of Sofosbuvir by using the chloro as an activating group.

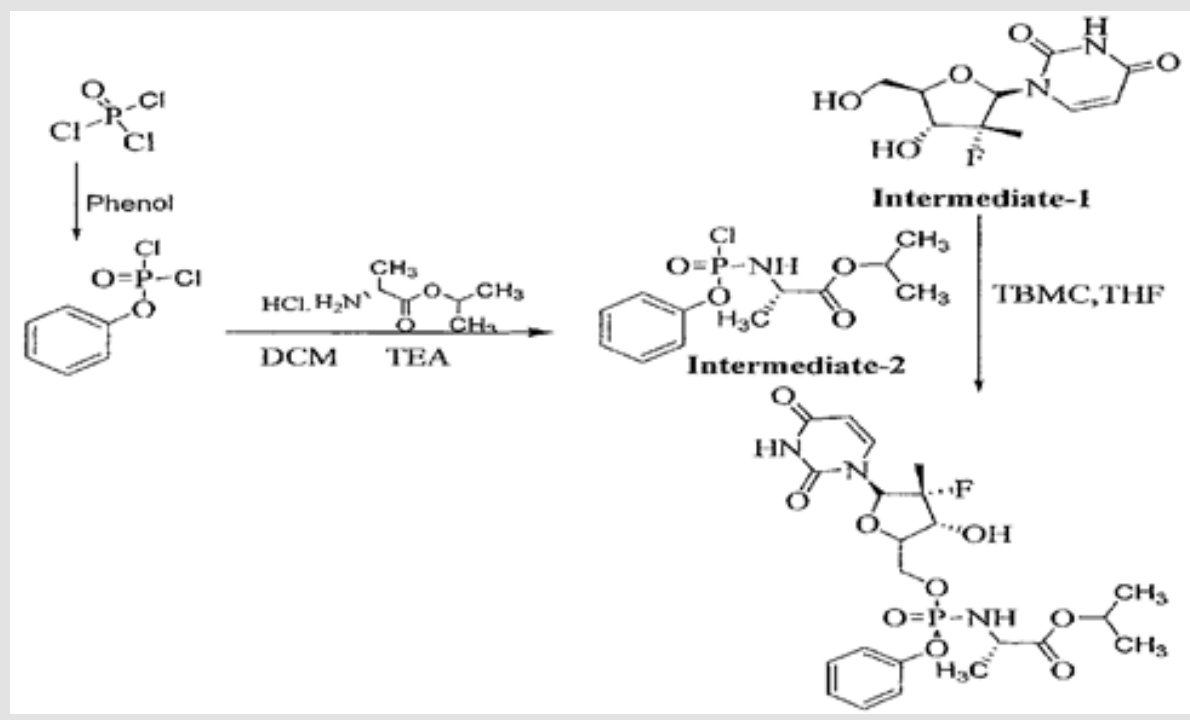

Figure 1: Sofosbuviris specifically disclosed in US 7,964,580. 
This patent has not provided any insight about the impurity concern as well as disclosure of any purity and their levels in the final product. The process was found to be cumbersome and involves the formation of many impurities. Further, the use of intermediate- 2 in the synthesis of Sofosbuvir yields the final API in poor yield, which was about $20 \%$. In view of this, it is necessary to develop a process resulting in the product, which is complying with the $1 \mathrm{CH}$ requirements of quality parameters besides industrially viable process. Ross et al in US 8,735,569 [10] disclose a process for the preparation of Sofosbuvir by protecting the hydroxyl group with pentafluoro phenol. The process is as disclosed below: (Figure 2) The present inventors found that the overall yield appears to be only $35-40 \%$ to get the desired isomer. This patent has not disclosed any generalized impurities formed during the process development. This patent has also not disclosed the content of total impurities formed (Table 1).

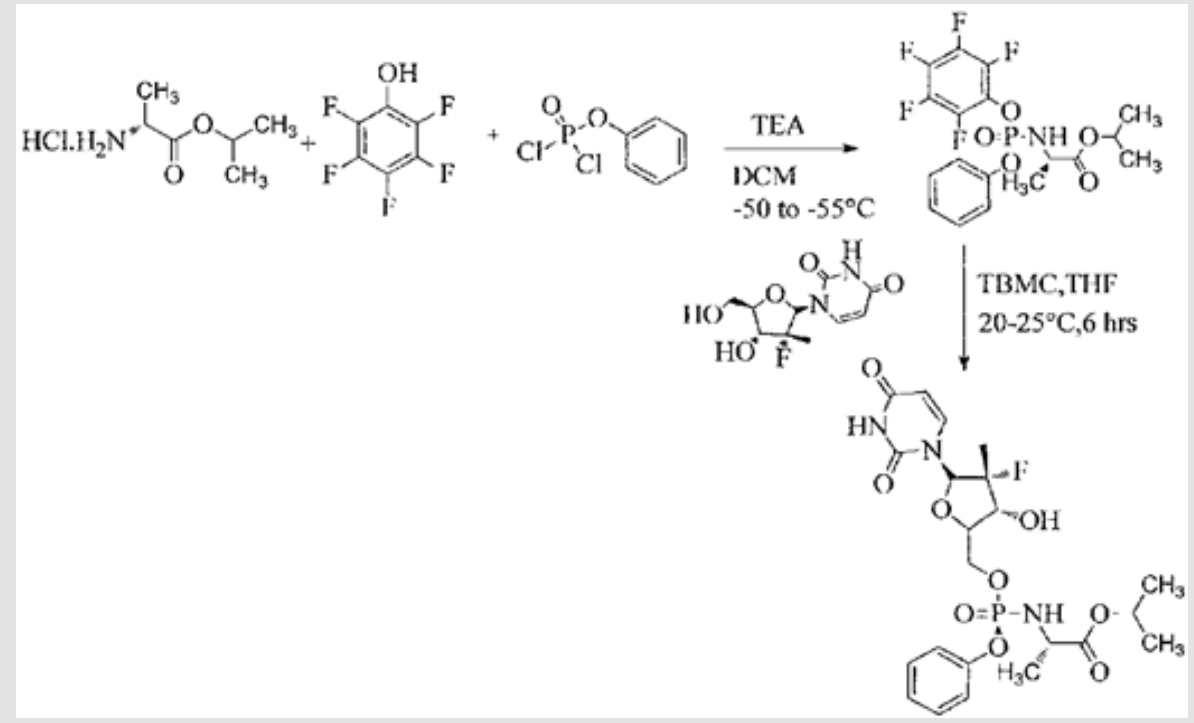

Figure 2.

Table 1.

\begin{tabular}{|c|c|}
\hline International nonproprietary name & Sponsor \\
\hline ABT-450 & AbbVie Inc. \\
\hline daclatasvir & Bristol-Myers Squibb Company \\
\hline dasabuvir & AbbVie Inc. \\
\hline ledipasvir & Gilead Sciences, Inc. \\
\hline ombitasvir & AbbVie Inc. \\
\hline simeprevir & Janssen Pharmaceutical Companies of Johnson \& Johnson \\
\hline sofosbuvir & Gilead Sciences Inc. \\
\hline
\end{tabular}

\section{W02011123668A2}

Patent application W02011123668A23 is a process patent with some claims referring to a compound in the form of a Markush structure The process comprises the preparation of sofosbuvir containing phosphorus. The process affords enantiomers or diastereomers of compounds having improved pharmacokinetic parameters relative to the active substance. Thus, claims are broad in nature and competitors may have to invent around this process. As per the WIPO ISR, several process-related claims cannot be considered novel. As per the available information The patent has not been granted yet, and is pending in Argentina, Australia, Canada, China, as well as China, Hong Kong SAR, the EAPO, the EPO, Japan, Republic of Korea, Singapore, and Thailand. a. Legal status is not available for published applications in Colombia, Costa Rica, Mexico, Peru and Viet Nam.

There are no litigation or opposition procedures reported.

\section{W02011123645A2}

Patent application W02011123645A2 [11] is a process patent for the preparation of the active compound. The patent covers a crystalline structure of nucleoside phosphoramidates, a general structural formula (Markush structure) of nucleoside phosphramidates, and a process of preparation of the active compound. Nucleoside phosphoramidates are used for the treatment of HCV infection. As per the WIPO ISR, several claims related to crystalline structures cannot be considered novel. 
As per the available information

a. The patent is pending in Argentina, Australia, Canada, China, as well as China, Hong Kong SAR, the EAPO, the EPO, Israel, Japan, Republic of Korea, Singapore, Thailand, and the United States.

b. Legal status is not available for published applications in Colombia, Costa Rica, Mexico, Peru, Uruguay and Viet Nam. There are no litigation or opposition procedures reported.

\section{W02010135569A1}

The patent application W02010135569A15 contains productby-process claims. A product- by-process claim is directed to a product that is defined by its process of preparation. This application claims diastereoisomeres of two specific nucleoside phosphoramidate prodrugs, their solvates, and polymorphic forms, as well as processes for their preparation and novel intermediates. As per the WIPO ISR, the application does not meet the requirement for unity of invention, i.e. it relates to not only one invention, but a group of closely related inventions. The subject matter of independent claim 1, 18-21 and dependent claims 2-6 of W02010135569A1 is new as it shows novelty and involves inventive steps [12] (Figure 3)

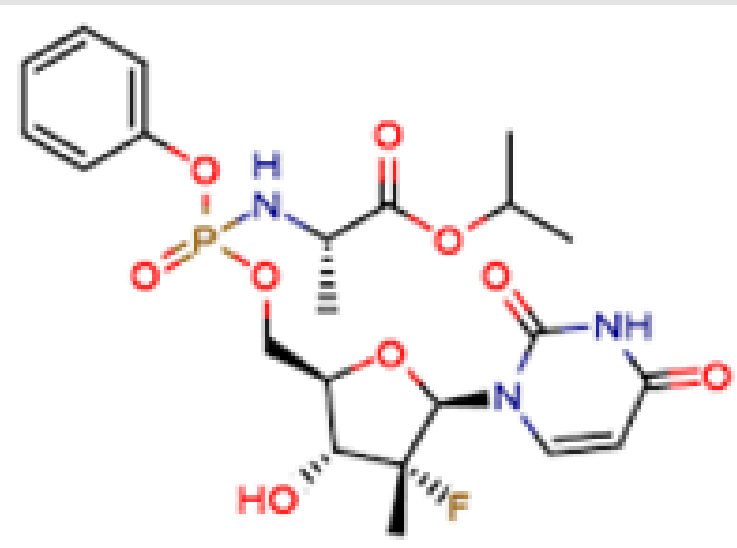

Figure 3.

\section{Prosecution at USPTO}

Four related United States patents are granted, US8563530B2, US8633309B2, US8642756B2, and US8629263B2. The US8563530B2 was allowed after the applicant amended the claims by clearly claiming nucleoside phosphoramidates and hydrate or solvate thereof in crystalline or crystal-like form. The US8633309B2 was allowed after applicant showed that $\mathrm{Rp}$ and $\mathrm{Sp}$ stereoisomers are more potent than the prior art. The US8642756B2 was allowed after the applicant amended the composition claims and limited the number of substituents in the basic structure. As per the available information

a. The patent has been granted in the United States. b. The patent is pending at various patent offices including Argentina, Australia, Canada, China, as well as China, Hong Kong SAR, the EAPO, the EPO, Israel, Japan, New Zealand, Republic of Korea, Singapore and the United States.

c. Legal status is not available for published applications in Colombia and Mexico.

There are no litigation or opposition procedures reported.

As per the available information

a. The patent has not yet been granted, and is pending in Argentina, China, Hong Kong SAR, and the EPO.

b. Legal status is not available for published applications in Japan and Uruguay.

There are no litigation or opposition procedures reported.

\section{W02012012465A1}

Patent application W02012012465A16 is a process patent claiming methods for preparing diastereomerically pure phosphoramidate prodrugs (Markush structure). As per the WIPO ISR, all 36 claims meet the requirement of novelty and industrial applicability. However, claims 1-7 of the present application lack inventive steps.

As per the available information

a. The patent has been granted in South Africa.

b. Patents are pending in Australia, Canada, China, as well as China, Hong Kong SAR, the EPO, Israel, Singapore, Republic of Korea, Ukraine and the United States.

c. Legal status is not available for published applications in Colombia, Costa Rica, the EAPO, Japan, Mexico, Morocco, Peru, and Viet Nam.

There are no litigation or opposition procedures reported.

\section{US8618076B2}

United States patent US8618076B2 covers a crystalline form of specific nucleoside phosphoramidate. The compound is useful for the treatment of HCV infection. The patent has been granted in the United States. The legal status for two related United States patent applications was not available. There are no litigation or opposition procedures reported [13].

\section{Preparation of Sofosbuvir}

Magnesium tert-butoxide $(8.6 \mathrm{~g}, 0.050)$ was added to the solution of 2'-deoxy-2,-fluoro-2'- methyluridine(6.3g, $0.0243 \mathrm{~mol})$ in $\mathrm{THF}(126 \mathrm{ml})$ at $25-30^{\circ} \mathrm{C}$ and maintained the reaction $30 \mathrm{~min}$ at $25-30^{\circ} \mathrm{C}$. Formula- VI derived from ethyl cyanoacetateoxime (10. $\mathrm{Og}$ ) in THF (31.5ml) was added to the reaction mass drop wise over the period of $30 \mathrm{~min}$ at $0-5^{\circ} \mathrm{C}$, allowed to $25-30^{\circ} \mathrm{C}$ and maintained for overnight. Quenched the reaction mass with $2 \mathrm{~N}$ HC1 solution $(70.0 \mathrm{~mL})$ at $10-15^{\circ} \mathrm{C}$, separated two layers and extracted aqueous 
layer with ethyl acetate $(31.5 \mathrm{~mL})$ and THF layer was concentrated and dissolved the residue in ethyl acetate $(252 \mathrm{~mL})$. Combined two ethyl acetate layers and washed with $5 \%$ sodium carbonate solution ,5\% brine solution successively and dried over sodium sulphate and filtered and concentrated to give3.5g of crude product stage-II (Sofosbuvir). Crude product was purified with dichloromethane $(37.8 \mathrm{~mL})$ and $\operatorname{MTBE}(18.9 \mathrm{~mL})$ stilted for $12 \mathrm{~h}$. Filtered the precipitated solid and dried to afford title product.

Yield: 0.6g

Chromatographic Purity (ByHPLC): >99.5 \%

\section{Preparation of Sofosbuvir}

t-butyl magnesium chloride $(75.0 \mathrm{ml}, 1.7 \mathrm{M}$ in THF) was added drop wise to the solution of 2,-deoxy-2'-fluoro-2'methyluridine $(15.8 \mathrm{~g})$ in $\mathrm{THF}(316.0 \mathrm{ml})$ at $0-5^{\circ} \mathrm{C}$ over a period of 40- $45 \mathrm{~min}$ under nitrogen atmosphere. Allowed reaction mass to $25-30^{\circ} \mathrm{C}$ and maintained for $30 \mathrm{~min}$ at $25-30^{\circ} \mathrm{C}$. Formula- VI derived from ethyl cyanoacetateoxime $(25 . \mathrm{Og})$ in THF $(79.0 \mathrm{ml})$ was added to the reaction mass drop wise over the period of $30 \mathrm{~min}$ at $0-5^{\circ} \mathrm{C}$, allowed to $25-30^{\circ} \mathrm{c}$ and maintained for overnight. Quenched the reaction mass with $2 \mathrm{NHCL}(158.0 \mathrm{~mL})$ by adjusting $\mathrm{pH}$ to 2.5 at 10 $15^{\circ} \mathrm{C}$, separated two layers and extracted aqueous layer with ethyl acetate $(79.0 \mathrm{~mL})$ and THF layer was concentrated and dissolved the residue in ethyl acetate(632. $0 \mathrm{~mL})$.

Combined two ethyl acetate layers and washed with brine solution $(316.0 \mathrm{~mL})$ then added $5 \%$ sodium carbonate solution $(316.0 \mathrm{~mL})$ at $10-15^{\circ} \mathrm{C}$ and agitated the reaction mixture for $10-15 \mathrm{~min}$ at $20-25{ }^{\circ} \mathrm{C}$ repeated this operation as thrice of times, then separated two layers then adjusted $\mathrm{pH}$ of the organic layer to $6.5-7.0$ by adding $\mathrm{IN} \mathrm{HCl}(1.5 \mathrm{~mL})$ at $10-15^{\circ} \mathrm{C}$, organic layers and washed the brine solution $(316.0 \mathrm{~mL})$ as twice of times followed by activated charcoal(1.5g) treatment and filtered through celite bed .Filtrate was concentrated to obtainsofosbuvir. Yield: $14.0 \mathrm{~g}$ While the foregoing pages provide a detailed description of the preferred embodiments of the invention, it is to be understood that the summary, description and examples are illustrative only of the core of the invention and non-limiting. Furthermore, as many changes can be made to the invention without departing from the scope of the invention, it is intended that all material contained herein be interpreted as illustrative of the invention and not in a limiting sense.

\section{Conclusion}

The search revealed patents filed with respect to sofosbuvir by the Sponsor as well as non-Sponsors. The sofosbuvir Sponsor patent collection comprises 21 different patents (patent families) with 279 family members published in 30 jurisdictions. The majority of these patent applications are still pending in the respective patent offices, 41 patents are granted. Sofosbuvir was a breakthrough new medication for the treatment of patients with chronic hepatitis C. Sofosbuvir has a number of ideal properties, including once daily dosing, no meal restrictions, few adverse effects, minimal drug-drug interactions, high genetic barrier to resistance, and relatively good safety and efficacy in patients with advanced liver disease. The use of sofosbuvir in combination with ribavirin was the first FDA-approved all oral therapy for hepatitis C. Of note, the activity against genotype 3 appears less than with genotype 2 and treatment of genotype 3 infection requires a longer all-oral course of treatment than with genotype 2 . Sofosbuvir is primarily used now in fixed-dose combinations.

\section{References}

1. Soriano V, Vispo E, De Mendoza C, Labarga P, Fernandez Montero JV, et al. (2013) Hepatitis C therapy with HCV NS5B polymerase inhibitors. Expert Opin Pharmacother14(9): 1161-1170.

2. Statement on a Nonproprietary Name Adopted by the USAN Council.

3. (2013) Drug Interactions with Investigational Hepatitis C Nucleotide Inhibitors. Sofosbuvir.

4. (2013) An Open-Label Study of Sofosbuvir/Ledipasvir Fixed-Dose Combination in subjects with nosocomial genotype $1 \mathrm{HCV}$ infection.

5. Murakami E, Tolstykh T, Bao H, Niu C, Steuer HM, et al. (2010) Mechanism of activation of PSI-7851 and its diastereoisomer PSI-7977. J Biol Chem 285(45): $34337-34347$.

6. Lam AM, Espiritu C, Bansal S, Micolochick Steuer HM, Niu C, et al. (2012) Genotype and subtype pro-ling of PSI-7977 as a nucleotide inhibitor of hepatitis C virus. Antimicrob Agents Chemother 56(6): 3359 -3368.

7. Stepanova M, Nader F, Cure S, Bourhis F, Hunt S, et al. (2014) Patients' preferences and health utility assessment with SF-6D and EQ-5D in patients with chronic hepatitis $\mathrm{C}$ treated with sofosbuvir regimens. Aliment Pharmacol Ther 40(6): 676-685.

8. Lawitz E, Mangia A, Wyles D, Rodriguez Torres M, Hassanein T, et al. (2013) Sofosbuvir for previously untreated chronic hepatitis C infection. N Engl J Med 368(20): 1878-1887.

9. Patent US 7,964,580.

10. Patent US 8,735,569.

11. Patent WO2011123668A2.

12. Patent W02012012465A1.

13. Patent US8618076B2. 


\section{ISSN: 2574-1241}

DOI: 10.26717/BJSTR.2019.21.003667

Krishna Sarma Pathy. Biomed J Sci \& Tech Res

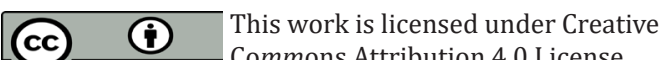

Submission Link: https://biomedres.us/submit-manuscript.php

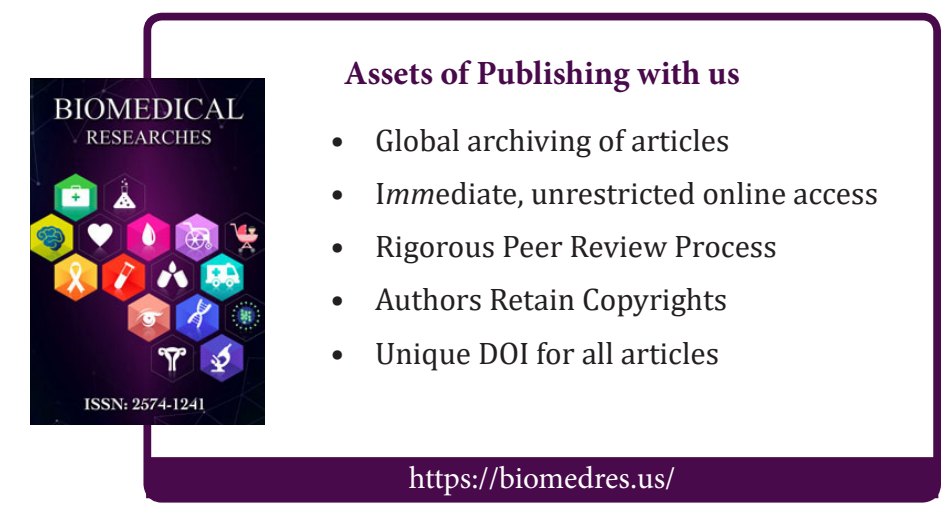

